\title{
Article
}

\section{Highland Barley Replaces Sorghum as Raw Material to Make Shanxi Aged Vinegar}

\author{
Huan Zhang ${ }^{1,2}$, Jingli Zhou ${ }^{3}$, Fanfan Lang ${ }^{3}$, Yu Zheng ${ }^{4}$ and Fusheng Chen $1,2, * \mathbb{C}$ \\ 1 Hubei International Scientific and Technological Cooperation Base of Traditional Fermented Foods, \\ Huazhong Agricultural University, Wuhan 430070, China; hz863@hotmail.com \\ 2 College of Food Science and Technology, Huazhong Agricultural University, Wuhan 430070, China \\ 3 Shanxi Zilin Vinegar Industry Co., Ltd., Taiyuan 030400, China; zhoujingli1110@126.com (J.Z.); \\ jszxlff@zlcy.com (F.L.) \\ 4 State Key Laboratory of Food Nutrition and Safety, College of Biotechnology, Tianjin University of Science \& \\ Technology, Tianjin 300457, China; yuzheng@tust.edu.cn \\ * Correspondence: chenfs@mail.hzau.edu.cn
}

check for updates

Citation: Zhang, H.; Zhou, J.; Lang, F.; Zheng, Y.; Chen, F. Highland Barley Replaces Sorghum as Raw Material to Make Shanxi Aged Vinegar. Appl. Sci. 2021, 11, 6039. https://doi.org/10.3390/app11136039

Academic Editor: Anet

Režek Jambrak

Received: 2 June 2021

Accepted: 25 June 2021

Published: 29 June 2021

Publisher's Note: MDPI stays neutral with regard to jurisdictional claims in published maps and institutional affiliations.

Copyright: (c) 2021 by the authors. Licensee MDPI, Basel, Switzerland. This article is an open access article distributed under the terms and conditions of the Creative Commons Attribution (CC BY) license (https:// creativecommons.org/licenses/by/ $4.0 /)$

\begin{abstract}
Highland barley (HB, Hordeum vulgare L. var. nudum Hook. f.), also known as naked or hulless barley, is a kind of cereal crop growing at high altitudes (4200-4500 m) around the world. In this study, $\mathrm{HB}$ vinegar (HBV) was prepared, using Tibetan $\mathrm{HB}$ as the main raw material, according to the process of Shanxi aged vinegar (SAV), a famous vinegar in China, in which sorghum is usually used as the main raw material. The related main compounds, such as alcohol and acetic acid, in the alcohol and acetic acid fermentation processes were monitored and analyzed, respectively. The flavor components in the aged vinegars were analyzed by headspace solid-phase microextraction, combined with gas chromatography-mass spectrometry, and compared with sorghum vinegar (SV), which was made, using sorghum as the raw material, based on the SAV process. The results revealed that at the alcohol fermentation stage, the alcohol content of HB mash was higher than that of the sorghum mash $(p<0.05)$, and at the acetic acid fermentation stages of HBV and SV, the total acid contents were 6.23 and $5.81\left(\mathrm{~g} \cdot 100 \mathrm{~mL}^{-1}\right.$ and $\left.p<0.05\right)$, respectively. After aging one and a half years, the contents of non-volatile acid, volatile acid, and ester compounds in HBV were higher than those in SV. Therefore, HB can replace sorghum as the raw material for making SAV. Based on a literature search, the comparison and analysis of the main components and volatile flavor compounds of HBV and SV were not studied before.
\end{abstract}

Keywords: highland barley; Shanxi aged vinegar; flavor compounds; gas chromatography-mass spectrometry

\section{Introduction}

Highland barley (HB, Hordeum vulgare L. var. nudum Hook. f.), also called naked or hulless barley (Qingke, in Chinese), is one of the variations of the Gramineae wheat family [1]. As a type of cereal crop grown in high altitudes (4200-4500 m) around the world, HB is characterized by early maturity, cold resistance, stable yield and wide adaptability [1,2]. In recent years, the planting area and yield of $\mathrm{HB}$ in China have increased steadily, reaching 25000 hectares and 1.1 million tons in 2019, respectively [3]. Besides starch, HB is also rich in $\beta$-glucan, dietary fiber, phenolic compounds, vitamin E, and other nutrients that are beneficial to human health [4-6]. Research has showed that HB possesses the functions of anti-oxidation, lowering blood pressure, adjusting blood lipid, and modifying intestinal flora, etc. [7-10]. HB has been produced into various foods such as noodles, HB wine, beverages, and so on [11-13]. Thus far, there has only been a few reports on HB used to brew vinegar [14]. In addition, based on our literature search, the comparison and analysis of main components and volatile flavor compounds (VFCs) of aged HBV and SV has not been done before. 
Vinegar, as a sour seasoning, is widely used in diets around the world. Due to the differences in regions, raw materials, and technologies, there are distinct varieties of vinegar in different countries and regions [15]. Generally, in Western countries such as Italy, Spain, Germany, the United States, and so on, vinegars are made mainly from fruits, including grape and apple, through liquid-state fermentation, and, thus, are called fruit vinegars [16]. In Eastern countries, such as China, Japan, and Korea, etc., vinegars are made mainly from sorghum, rice, corn, wheat or other cereals rich in starch by solid-state fermentation (SFP), and, thus, are called cereal vinegars [17]. In China, there are various kinds of cereal vinegars [18]. Among them, Shanxi aged vinegar (SAV) is one of the most famous cereal vinegars produced by SFP, and it is usually produced with sorghum as the main raw material, and bran, rice or millet husk as auxiliary materials. In the SAV process, some unique processes occur, for instance, after acetic acid fermentation (AAF), about 30\% vinegar paste (called Cupei, 醋醅 in Chinese) is heated, and new (fresh) vinegar is aged at least half a year before bottling and entering the market [19]. All these unique processes give SAV its characteristic thickness, mellow sourness, and delicate fragrance, making it different from other vinegars $[20,21]$.

In the current study, HB replaced sorghum to make HB vinegar (HBV) based on the SAV process. The composition of $\mathrm{HB}$ and sorghum was analyzed, changes of main compounds including alcohol and total acid, etc. during the production processes of $\mathrm{HBV}$ and sorghum vinegar (SV) were detected and compared, and the VFCs of HBV and SV, aged one and a half years, were determined by headspace solid phase microextraction-gas chromatography-mass spectrometry (HS-SPME/GC-MS). The results showed that HB is an alternative raw material that can be used to make the cereal vinegar.

\section{Materials and Methods}

\subsection{Raw Materials}

Tibetan highland barley (HB), sorghum, and starters, including Daqu, Kuaiqu and Jiumu, were provided by Shanxi Zilin Vinegar Industry Co., Ltd., Shanxi Province, China. Daqu, which contains various hydrolases such as amylase and protease, is made of a mixture of barley, wheat, and pea by spontaneous fermentation [22]. Kuaiqu, which contains high amylase and glucoamylase activity, is a type of starter prepared with Aspergillus niger [23]. Jiumu is another starter containing a large number of yeasts, such as Saccharomyces cerevisiae [24].

\subsection{The Process of Vinegar Production}

The production process (Figure 1) of vinegars in the current study includes saccharification, alcoholic fermentation (AF), acetic acid fermentation (AAF), heating, drenching, and aging based on the SAV process [24].

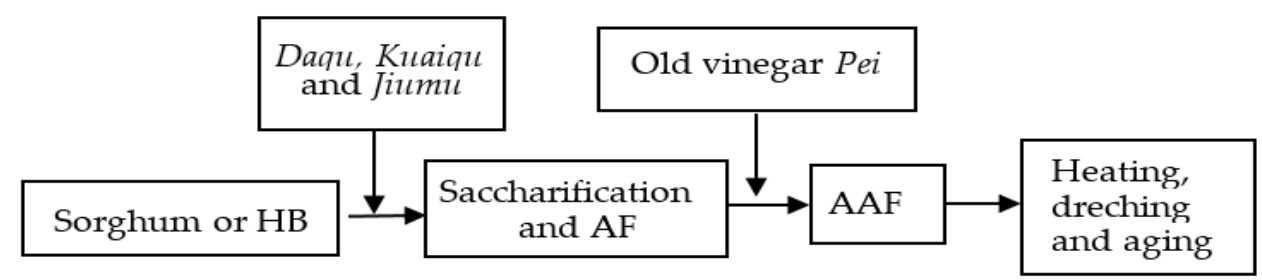

Figure 1. The process flow chart for Shangxi aged vinegar.

Briefly, after the raw material (HB or sorghum) is crushed into pieces, it is placed in a ceramic container, and then mixed evenly with Daqu and Kuaiqu powder, Jiumu, and water to make the fermentative mash according to the ingredient ratios listed in Table 1. During the first three days, the mash is stirred and mixed twice a day, and further standing fermentation occurs until 16 days (AF). After that, the vinegar paste is made by mingling the mash evenly with $100 \mathrm{~kg}$ of raw materials, including $50 \mathrm{~kg}$ of bran (Table 1) and the old vinegar paste (including acetic acid bacteria) from the last production, to start AAF for 
10 days in the ceramic container, turning over the vinegar paste twice a day. Then, 30\% vinegar paste is heated for 5 days, during which the temperature of the vinegar paste is gradually increased from $30^{\circ} \mathrm{C}$ to $90^{\circ} \mathrm{C}$ in the first 3 days, then decreased to $30^{\circ} \mathrm{C}$ on the fifth day, resulting in a color change from light yellow to brown. Finally, the heated vinegar paste is blended with the unheated vinegar paste (about $70 \%$ ), and leached with saline to obtain the new (fresh) vinegar, which is aged for one and a half years in an open pottery container, into aged vinegar.

Table 1. Ingredient proportion for vinegar production.

\begin{tabular}{ccccccc}
\hline \multirow{2}{*}{ Categories } & \multicolumn{5}{c}{ Ingredient Proportion (Kg) } \\
\cline { 2 - 7 } & Raw Material & Daqu & Kuaiqu & Jiumu & Material: $\mathbf{H}_{\mathbf{2}} \mathbf{O}$ & Bran \\
\hline HBV & $100(\mathrm{HB})$ & 45 & 15 & 0.20 & $1: 4.0$ & $50 / 100 \mathrm{HB}$ \\
SV & 100 (Sorghum) & 45 & 15 & 0.20 & $1: 4.0$ & $50 / 100$ Sorghum \\
\hline
\end{tabular}

HBV: Highland barley vinegar; and SV: Sorghum vinegar.

\subsection{Determination of Physicochemical Parameters}

\subsection{1. $\beta$-glucan Determination}

The $\beta$-glucan contents of the samples were analyzed by the Megazyme mixed $\beta$ glucan detection kit produced by Beijing Micro Wise Co., Ltd., Beijing, China, following the manufacturer's instructions. In brief, the process included sample preparation and enzymatic hydrolysis and $\beta$-glucan determination.

Sample preparation: for $\mathrm{HB}$ and sorghum, a $0.2 \mathrm{~g}$ (100 mesh) sample was treated with a $10 \mathrm{~mL} \mathrm{50 \%} \mathrm{ethanol} \mathrm{solution} \mathrm{for} 10 \mathrm{~min}$ at $80^{\circ} \mathrm{C}$ in the water bath, and then centrifuged at $2000 \mathrm{rpm}$ for $10 \mathrm{~min}$. The centrifugal sediment was treated once with $50 \%$ ethanol solution at the above-mentioned conditions. The final precipitate was used for the next enzymatic hydrolysis and $\beta$-glucan determination. For the alcoholic fermentation mashes and vinegars, three times the volume $(15 \mathrm{~mL})$ of $95 \%(V / V)$ ethanol solution was added into a $5 \mathrm{~mL}$ sample. After shaking violently, the mixture stood for $5 \mathrm{~min}$, and was centrifuged at $2000 \mathrm{rpm}$ for $10 \mathrm{~min}$. The centrifugal sediment was treated with a $10 \mathrm{~mL} \mathrm{50 \%} \mathrm{ethanol}$ solution, and the mixture was centrifuged at $2000 \mathrm{rpm}$ for $10 \mathrm{~min}$ to get the final precipitate for enzymatic hydrolysis and $\beta$-glucan determination.

Enzymatic hydrolysis and $\beta$-glucan determination: the precipitate from the sample preparation was dispersed into a $0.2 \mathrm{~mL} 50 \%$ ethanol solution by shaking violently. After that, $4 \mathrm{~mL}$ of phosphate buffer $(20 \mathrm{mM}$, pH6.5) was added and put into boiling water for $5 \mathrm{~min}$ to completely dissolve the precipitate. Then, the mixture was moved to the water bath at $50{ }^{\circ} \mathrm{C}$ for about $10 \mathrm{~min}$, and a $0.2 \mathrm{~mL} 50 \mathrm{U} / \mathrm{mL}$ lichenase solution from the kit was supplemented, mixed well, and kept for $60 \mathrm{~min}$ in the water bath. A $5 \mathrm{~mL}$ acetate buffer (200 mM, pH 4.0) was then supplemented, mixed well, and centrifuged at $2000 \mathrm{rpm}$ for 10 $\mathrm{min}$. Then, $1 \mathrm{~mL}$ of supernatant and $0.1 \mathrm{~mL} 2 \mathrm{U} / \mathrm{mL} \beta$-glucosidase solution from the kit were mixed evenly, and kept at $50{ }^{\circ} \mathrm{C}$ for $10 \mathrm{~min}$. The glucose content in the mixture was detected by glucose oxidase, and the $\beta$-glucan contents of samples were calculated by the following formula:

$$
\mathrm{H}=\Delta \mathrm{A} \times \mathrm{F} \times 9.4 \times 10^{-6} / \mathrm{W} \times 0.9 \times 100
$$

where $H$ is the percentage of $\beta$-glucan in the sample; $\Delta \mathrm{A}$ is the difference between the absorbance values of the sample and the blank; $F$ is the ratio of $100 \mu \mathrm{g}$ glucose divided by the absorbance value of $100 \mu \mathrm{g}$ glucose; 9.4 is the volume correction factor; $\mathrm{W}$ is the sample weight or volume ( $\mathrm{g}$ or $\mathrm{mL}$ ); and 0.9 is the coefficient of glucose condensation into $\beta$-glucan.

\subsubsection{Total Flavonoids Analysis}

Total flavonoids content (TFC) of the vinegar samples was detected by using a colorimetric assay, with minor modifications, according to the method described in the literature [25]. 
Briefly, $2.5 \mathrm{~mL}$ of vinegar and $0.3 \mathrm{~mL}$ of $\mathrm{NaNO}_{2}(5 \%)$ were mixed. After $6 \mathrm{~min}, 0.3 \mathrm{~mL}$ of $\mathrm{Al}\left(\mathrm{NO}_{3}\right)_{3}(10 \%)$ was added into the mixture, mixed well, and left to stand for $6 \mathrm{~min}$. Next, $4 \mathrm{~mL}$ of $\mathrm{NaOH}(4 \%)$ was added into the mixture, then the mixture volume was set to $25 \mathrm{~mL}$ with distilled water, and blended well. The absorbance was measured at $510 \mathrm{~nm}$. Rutin was used as the standard and the tests were performed in triplicate.

\subsubsection{Total Acid and Ester Analyses}

The total acid (TA) and total ester (TE) were analyzed following the continuous potentiometric titration method described in the literature [26].

For TA analysis, $10 \mathrm{~mL}$ of vinegar was put into a $100 \mathrm{~mL}$ volumetric flask, and the volume was set to $100 \mathrm{~mL}$ with distilled water. Then, $20 \mathrm{~mL}$ of solution was taken from the volumetric flask to a $250 \mathrm{~mL}$ beaker, and $60 \mathrm{~mL}$ of distilled water was added and mixed. Then, a $0.1 \mathrm{M} \mathrm{NaOH}$ solution was used to titrate the $\mathrm{pH}$ value to 8.2 , which was monitored by the $\mathrm{pH}$ meter (PHS-25, Shanghai Yidian Scientific Instrument Co., Ltd., Shanghai, China). Finally, the TA contents of the samples were calculated based on $0.1 \mathrm{M} \mathrm{NaOH}$ standard solution consumption.

For TE determination, we transferred the titrated vinegar sample from the TA analysis into a $350 \mathrm{~mL}$ round bottom beaker, added $25 \mathrm{~mL}$ of $0.1 \mathrm{M} \mathrm{NaOH}$ solution, and mixed well. After a condenser was connected with the beaker, the mixture was reacted (saponified) for $0.5 \mathrm{~h}$ in boiling water. After the mixture was cooled to room temperature and moved to a $250 \mathrm{~mL}$ beaker, we used a $0.1 \mathrm{M} \mathrm{H}_{2} \mathrm{SO}_{4}$ solution to titrate it to $\mathrm{pH}$ 9.5. The TE contents of the samples were calculated based on $0.1 \mathrm{M} \mathrm{H}_{2} \mathrm{SO}_{4}$ solution consumption. The TE contents were expressed as the content of ethyl acetate.

\subsubsection{Other Physicochemical Indexes Determination}

The determination of starch, protein, and fat in raw materials (HB and sorghum), according to the literature [27], and the amount of alcohol, amino acid nitrogen, reducing sugar, etc. in the alcohol fermentation mash and vinegar paste were detected by the methods described in the literature [28-32].

\subsection{Analyses of Volatile Flavor Compounds in Vinegars}

The VFCs of vinegars were extracted by HS-SPME (Supelco, Bellefonte PA, USA) and determined by GC-MS/MS (Shimadzu QP2010, Shimadzu Corporation, Kyoto, Japan). To do so, $2 \mathrm{~mL}$ of vinegar and $6.0 \mathrm{~mL}$ of distilled water were placed in a $20 \mathrm{~mL}$ headspace bottle; $1 \mathrm{~g}$ of $\mathrm{NaCl}$ and a magnetic agitator were added into the bottle, then the bottle cap was tightly screwed into place. After the solution was agitated and equilibrated at $60^{\circ} \mathrm{C}$ for $5 \mathrm{~min}$, the dimethylsiloxane (DVB/CAR/PDMS) fiber was inserted into the bottle through the cap and headspace absorption was performed for $40 \mathrm{~min}$. Upon completion, the fiber was inserted into the injection port $\left(220^{\circ} \mathrm{C}\right)$ of the GC-MS instrument to desorb for $5 \mathrm{~min}$. The carrier gas was pure helium with flow rate of $1 \mathrm{~mL} / \mathrm{min}$ with a separation ratio of 5:1. The initial temperature of the program, $40{ }^{\circ} \mathrm{C}$, was increased to $150{ }^{\circ} \mathrm{C}$ at a rate of $4{ }^{\circ} \mathrm{C} / \mathrm{min}$, then increased to $250{ }^{\circ} \mathrm{C}$ at a rate of $8{ }^{\circ} \mathrm{C} / \mathrm{min}$ and kept for $6 \mathrm{~min}$. MS conditions: the EI ionization source temperature was $230^{\circ} \mathrm{C}$, the energy was $70 \mathrm{eV}$, and the scanning range was set at 35-500 $\mathrm{m} / \mathrm{z}$. The VFCs were identified by comparing their mass spectra with those from the NIST 11 library, and the concentrations of the VFCs were estimated by the concentration of the internal standard substance (2-Octanol) and its peak area with compounds [33].

\subsection{Statistical Analysis}

The experiments were performed in three repetitions and the data were expressed as the mean \pm standard deviation (SD). The significance of the differences between groups was analyzed by the analysis of variance (ANOVA) using GraphPad Prism version 8.0 (GraphPad Software, San Diego, CA, USA), and a $p$-value of $<0.05$ was considered as the threshold for statistical significance. The heatmap was drawn by TBtools [34]. 


\section{Results and Discussion}

\subsection{Ingredients Analyses of Raw Materials}

The main components in HB and sorghum, including starch, protein, fat and $\beta$-glucan, were analyzed. The results (Figure 2) revealed that the contents of starch in HB and sorghum were high, up to $75.47 \%$ and $68.06 \%$, respectively, while the contents of protein and fat in both raw materials were relatively low by comparison. Moreover, HB also contained $5.72 \% \beta$-glucan, but the sorghum did not contain $\beta$-glucan. Compared with sorghum, HB contained the higher content of starch and protein, and, thus, HB may be more suitable as the raw material of SAV.

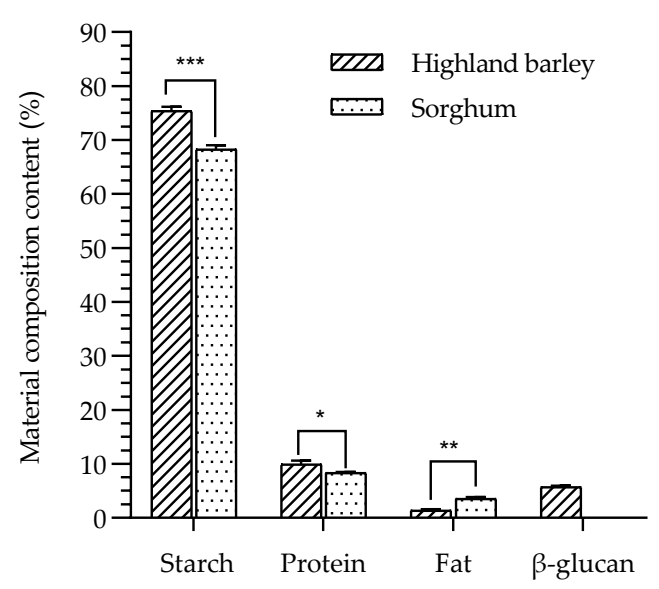

Figure 2. Contents of main substances in highland barley and sorghum; ${ }^{*} p<0.05 ;{ }^{* *} p<0.01$; and *** $p<0.001$.

\subsection{Constituent Analyses during Vinegar Production}

\subsubsection{Constituents in Alcohol Fermentation Mashes}

Alcohol fermentation (AF) is one of the processes in SAV production. During AF, the starch is converted into a reducing sugar (RS) by amylase and glucoamylase from Daqu and Kuaiqu, then the RS is converted into alcohol, which is the main substrate for AAF, by Saccharomyces cerevisiae from Jiumu [35]. The component contents in the mashes of HB and sorghum at end of AF (16 days) are shown in Table 2.

Table 2. The component contents in alcohol fermenting mashes of $\mathrm{HB}$ and sorghum.

\begin{tabular}{|c|c|c|c|c|c|}
\hline Categories & Alcohol (\%) & TA $\left(\mathrm{g} \cdot 100 \mathrm{~mL}^{-1}\right)$ & $\begin{array}{l}\text { Residual Starch } \\
\left.\text { (g.100 } \mathrm{mL}^{-1}\right)\end{array}$ & $\begin{array}{l}\text { Residual RS } \\
\left(\mathrm{g} \cdot 100 \mathrm{~mL}^{-1}\right)\end{array}$ & $\begin{array}{l}\beta \text {-glucan } \\
\left(\mathrm{mg} \cdot \mathrm{L}^{-1}\right)\end{array}$ \\
\hline HB AF mash & $8.35 \pm 0.07$ & $2.36 \pm 0.04$ & $2.49 \pm 0.01$ & $0.44 \pm 0.01$ & $6.74 \pm 0.08$ \\
\hline Sorghum AF mash & $7.67 \pm 0.18$ & $2.32 \pm 0.07$ & $2.02 \pm 0.02$ & $0.30 \pm 0.02$ & - \\
\hline
\end{tabular}

HB: Highland barley; AF: alcohol fermentation; TA: total acid; RS: reducing sugar; -: none detected. Values are presented as means \pm standard deviations $(n=3)$.

Compared with the sorghum AF mash, the contents of alcohol and residual starch were higher in HB AF mash $(p<0.05)$, while the contents of TA and residual RS were just a little higher in the HB AF mash $(p>0.05$; Table 2$)$. A trace amount of $\beta$-glucan $\left(6.74 \mathrm{mg} \cdot \mathrm{L}^{-1}\right)$ was also detected in the HB AF mash, but none was detected in the sorghum AF mash (Table 2).

\subsubsection{Changes of Alcoholicity and TA Contents during AAF}

Acetic acid fermentation (AAF) is another key process for vinegar production, which is the main stage for acetic acid production and also for flavor formation $[23,36]$. The changes of alcohol and TA concentrations during AAF of HBV and SV were analyzed and are shown in Figure 3. 


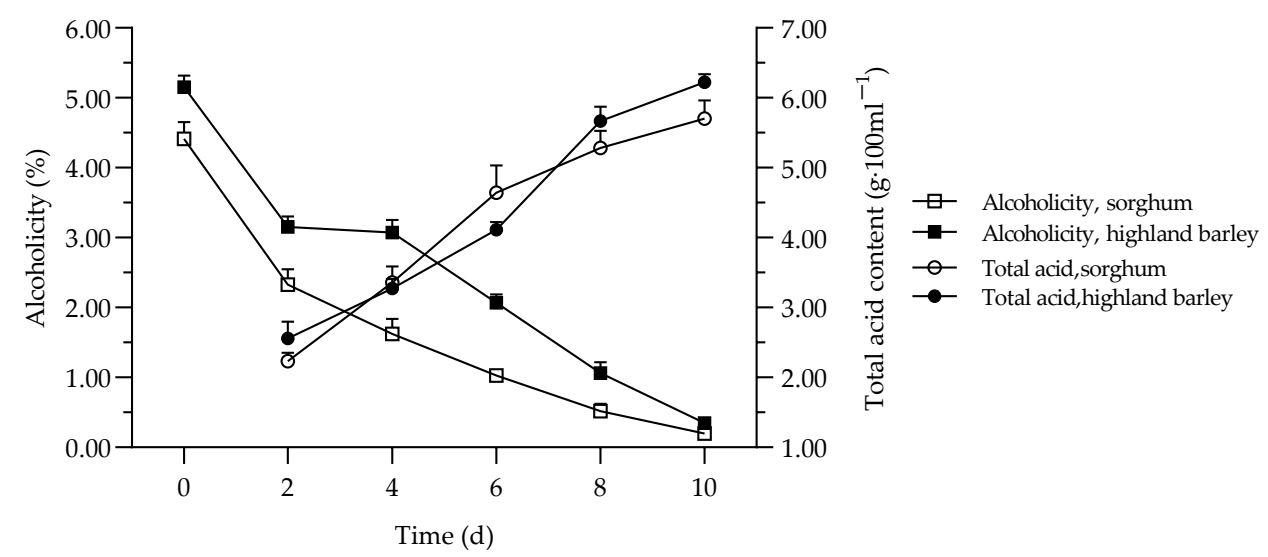

Figure 3. Changes of alcohol and TA concentrations during AAF.

As expected, during the AAF processes, the alcohol and TA concentrations showed downward and upward trends, respectively (Figure 3). At the end of AAF (at 10th day), the TA contents reached up 6.23 and $5.81\left(\mathrm{~g} \cdot 100 \mathrm{~mL}^{-1}\right)$ in HBV and SV pastes, respectively, there was a significant difference $(p<0.05)$, and the alcohols were almost exhausted in both vinegar pastes, with less than $0.5 \%$ alcohol left.

\subsubsection{Analyses of the Main Components in New and Aged Vinegars}

Aging in an open pottery container is a unique process of SAV production [19]. In the ageing process of SAV, with the evaporation of volatile substances and water, the volume and viscosity (thickness) of the vinegar decreases and increases, respectively, and the pungent taste reduces, which makes the vinegar more mellow, soft, and harmonious. Meanwhile, due to the esterification and Maillard reactions, various components in vinegar also change considerably [37]. The main composition of the new (fresh) and aged (one and a half years) HBV and SV were determined and compared (Table 3).

Table 3. The main composition in HBV and SV before and after aging.

\begin{tabular}{|c|c|c|c|c|}
\hline \multirow{2}{*}{ Items } & \multicolumn{2}{|c|}{ New Vinegars } & \multicolumn{2}{|c|}{ Aged Vinegars } \\
\hline & HBV & SV & HBV & SV \\
\hline $\mathrm{TA}\left(\mathrm{g} \cdot 100 \mathrm{~mL}^{-1}\right)$ & $4.94 \pm 0.04$ & $4.93 \pm 0.02$ & $6.65 \pm 0.06$ & $6.55 \pm 0.05$ \\
\hline Non-volatile acid $\left(\mathrm{g} \cdot 100 \mathrm{~mL}^{-1}\right)$ & $1.62 \pm 0.01$ & $1.66 \pm 0.02$ & $2.75 \pm 0.04$ & $1.94 \pm 0.02$ \\
\hline Amino acid nitrogen $\left(\mathrm{g} \cdot 100 \mathrm{~mL}^{-1}\right)$ & $0.20 \pm 0.01$ & $0.21 \pm 0.02$ & $0.31 \pm 0.04$ & $0.31 \pm 0.02$ \\
\hline $\mathrm{RS}\left(\mathrm{g} \cdot 100 \mathrm{~mL}^{-1}\right)$ & $1.24 \pm 0.01$ & $1.24 \pm 0.01$ & $0.99 \pm 0.02$ & $0.88 \pm 0.04$ \\
\hline Salt $\left(\mathrm{g} \cdot 100 \mathrm{~mL}{ }^{-1}\right)$ & $0.89 \pm 0.02$ & $0.82 \pm 0.03$ & $1.03 \pm 0.03$ & $1.53 \pm 0.03$ \\
\hline Soluble salt-free solid $\left(\mathrm{g} \cdot 100 \mathrm{~mL}^{-1}\right)$ & $9.46 \pm 0.05$ & $8.16 \pm 0.02$ & $14.10 \pm 0.11$ & $13.64 \pm 0.04$ \\
\hline $\mathrm{TE}\left(\mathrm{g} \cdot 100 \mathrm{~mL} \mathrm{~L}^{-1}\right)$ & $3.13 \pm 0.06$ & $3.50 \pm 0.03$ & $2.70 \pm 0.02$ & $3.35 \pm 0.05$ \\
\hline $\mathrm{TF}\left(\mathrm{mg} \cdot 100 \mathrm{~mL}^{-1}\right)$ & $73.91 \pm 0.19$ & $88.71 \pm 0.03$ & $109.00 \pm 1.41$ & $113.00 \pm 1.39$ \\
\hline Ligustrazine $\left(\mathrm{mg} \cdot 100 \mathrm{~mL}^{-1}\right)$ & $3.05 \pm 0.05$ & $3.35 \pm 0.04$ & $5.49 \pm 0.08$ & $9.13 \pm 0.02$ \\
\hline$\beta$-glucan & - & - & - & - \\
\hline Volume (L) & $100.00 \pm 0.71$ & $100.00 \pm 0.98$ & $68.00 \pm 0.69$ & $69.00 \pm 0.92$ \\
\hline
\end{tabular}

HBV: Highland barley vinegar; SV: Sorghum vinegar; New vinegar: unaged vinegar; Aged vinegar: aged for one and a half years; TA: total acid; RS: reducing sugar; TE: total ester; TF: total flavonoid; -: Not detected. Values are presented as means \pm standard deviations $(n=3)$. The numbers in bold in the table indicate that the index values in aged vinegars are less than those in new vinegars.

The results (Table 3 ) revealed that, compared with the new vinegars, with the exception of RS and TE, the main components of the aged vinegars were improved to a certain extent. At the end of ageing, due to the evaporation of volatile components and water in vinegars, the volumes of aged HBV and SV were only about two-thirds of those of the new vinegars, and the viscosity and consistency of the aged vinegars were also improved to a great extent. The RS reduction in aged vinegars may be caused by the RS consumption of the Maillard reaction during the ageing process, while the TE decreases may be due to its 
high volatility [38]. Both the TA and non-volatile acid in the aged vinegars were greatly improved. The TA increase may be mainly caused by the increase of the contents of the non-volatile acids [39]. A higher concentration of non-volatile acids, such as lactic acid, succinic acid, and gluconic acid, together with a higher content of soluble salt-free solid can neutralize and reduce the pungent smell of volatile acids, such as acetic acid, so as to make the vinegars more soft and harmonious $[40,41]$. The characteristic component of $\mathrm{SAV}$, ligustrazine (2,3,5,6-tetramethylpyrazine), also one of the products of the Maillard reaction [42], and TF, both of which have many physiological functions, such as dilating blood vessels, lowering blood pressure, and improving cerebral blood circulation, anticancer, anti-bacteria, anti-virus, and antioxidant functions, etc. [43-46], were also greatly improved after aging. Ligustrazine and TF are considered to be the material basis of various physiological functions of SAV $[47,48]$.

$\beta$-glucan is one of the main compounds, and the most widely studied bioactive ingredient, in $\mathrm{HB}$, which can affect energy metabolism, lower blood glucose, and increase insulin response [7]. Unfortunately, $\beta$-glucan was not detected in the new and old vinegars (Table 3). In particular, in HBV prepared by HB, with a high content of $\beta$-glucan (5.72\%, Figure 2$), \beta$-glucan was not detected even though a trace of $\beta$-glucan $\left(6.74 \mathrm{mg} \cdot \mathrm{L}^{-1}\right)$ was detected in HB AF mash at the end of the AF stage (Table 2). This may be due to the poor water-solubility of $\beta$-glucan, meaning that most of the $\beta$-glucan was left in the vinegar residue, while a small amount of water-soluble $\beta$-glucan might be digested by microorganisms from Daqu and other starters [49].

Compared with the aged SV, the contents of TA, RS, salt, soluble salt-free solid, and TE had no significant difference $(p>0.05)$, while the content of non-volatile acid in the aged HBV was significantly $(p<0.05)$ high and the contents of TE, TF, and ligustrazine were significantly $(p<0.05)$ lower (Table 3$)$.

\subsection{Volatile Flavor Compounds Analysis of Aged Vinegars}

HS-SPME/GC-MS was used to determine the VFCs in the aged HBV and SV. Acetic acid as the main compound and also the very important VFC in vinegars, which the detection results had great inaccuracy by HS-SPME/GC-MS due to the low efficiencies of solid phase extraction and desorption [50]. Therefore, acetic acid was not included in the VFCs of HBV and SV (Figure 4; Supplementary Materials, Table S1).

Based on the VFCs in the aged HBV and SV by HS-SPME/GC-MS (Table S1), a total of 102 VFCs were found in both vinegars, including 60 common VFCs, and 24 and 18 unique VFCs from the aged HBV and SV, respectively, which were mainly classified into acids, alcohols, esters, aldehydes, furans, ketones, and pyrazines, etc. (Table 4; Table S1).

Table 4. VFCs classification in aged HBV and SV.

\begin{tabular}{|c|c|c|}
\hline \multirow{2}{*}{ Species } & \multicolumn{2}{|c|}{ Concentrations $\left(\mathrm{mg} \cdot \mathrm{L}^{-1}\right)$} \\
\hline & HBV & SV \\
\hline Acids & $2114.14 \pm 30.50 /(11)$ & $1644.47 \pm 36.39 /(12)$ \\
\hline Alcohols & $2432.88 \pm 59.03 /(14)$ & $4415.19 \pm 94.08 /(12)$ \\
\hline Esters & $2753.62 \pm 93.96 /(22)$ & $1553.37 \pm 48.56 /(20)$ \\
\hline Aldehydes & $1180.72 \pm 25.82 /(14)$ & $1384.15 \pm 29.09 /(13)$ \\
\hline Furans & $65.52 \pm 0.76 /(1)$ & $97.49 \pm 2.75 /(2)$ \\
\hline Ketones & $301.95 \pm 7.74 /(9)$ & $407.67 \pm 9.03 /(7)$ \\
\hline Pyrazines & $806.85 \pm 6.18 /(6)$ & $1066.57 \pm 11.79 /(4)$ \\
\hline Others & $410.30 \pm 3.04 /(7)$ & $459.35 \pm 10.71 /(8)$ \\
\hline
\end{tabular}




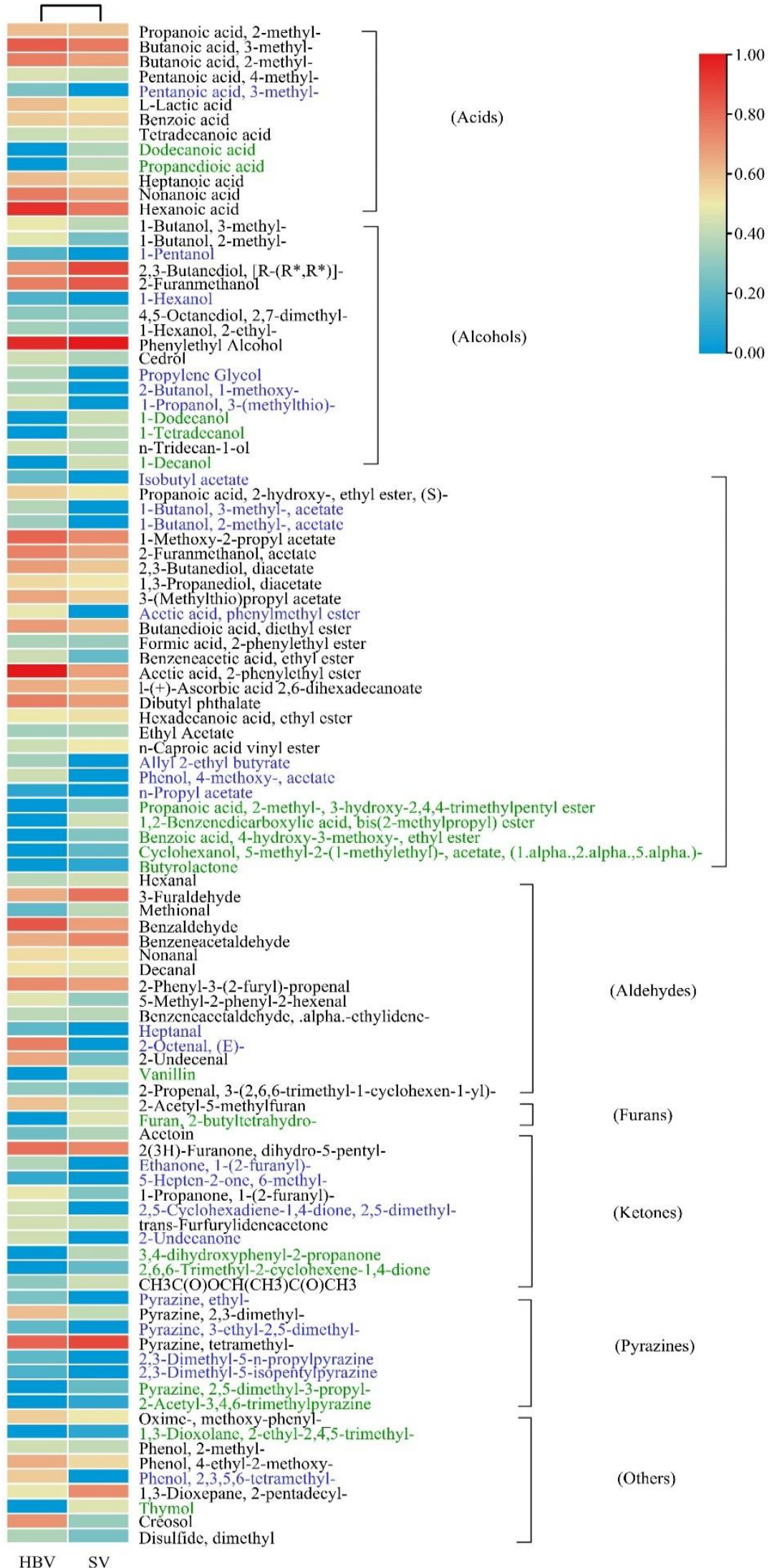

(Esters)

Figure 4. Heatmap of VFCs from aged HBV and SV. The black fonts indicate the common VFCs, while the blue and green fonts indicate the unique VFCs in both of aged HBV and SV, respectively. 
The major VFCs in aged HBV and SV are shown in Table 5. Among them, 3-methylbutanoic acid, [R-( $\left.\left.R^{*}, R^{*}\right)\right]-2,3-b u t a n e d i o l$, phenylethyl alcohol, acetic acid 2-phenylethyl ester, benzaldehyde and tetramethylpyrazine, as main VFCs, were also found in SAV [21], possessing a cheesy [51,52], fruity [53,54], peachy [55], almondy [56], and nutty [21] smell, respectively. We also discovered that the contents of hexanoic acid, 2-furanmethanol acetate, acetic acid 2-phenylethyl ester, benzaldehyde, (E)-2-Octenal, 2-undecenal, and creosol were higher in HBV than those in SV (Table 4), while other VFCs were higher in SV than those in HBV. The SAV VFCs mainly came from the raw materials and the fermentation, heating, and aging process $[57,58]$. The VFC differences between BHV and SV were mainly produced by the components of the raw materials and their derivatives in the fermentation, heating and aging process since, in this study, the production process for HBV and SV was identical. In the future, the VFC differences in BHV and SV should be further studied.

Table 5. Summary of main VFCs in aged HBV and SV.

\begin{tabular}{|c|c|c|c|}
\hline & \multirow{2}{*}{ VFCs } & \multicolumn{2}{|c|}{ Concentrations $\left(\mathrm{mg} \cdot \mathrm{L}^{-1}\right)$} \\
\hline & & HBV & SV \\
\hline \multirow[t]{2}{*}{ Acids } & 3-Methyl- butanoic acid & $563.83 \pm 10.40$ & $458.56 \pm 13.12$ \\
\hline & Hexanoic acid & $808.51 \pm 6.02$ & $431.15 \pm 4.84$ \\
\hline \multirow{3}{*}{ Alcohols } & {$\left[\mathrm{R}-\left(\mathrm{R}^{*}, \mathrm{R}^{*}\right)\right]-2,3$-Butanediol } & $248.85 \pm 3.43$ & $1043.19 \pm 30.54$ \\
\hline & 2-Furanmethanol & $411.11 \pm 7.15$ & $747.36 \pm 10.15$ \\
\hline & Phenylethyl alcohol & $1578.52 \pm 34.31$ & $2478.52 \pm 55.52$ \\
\hline \multirow[t]{2}{*}{ Esters } & 2-Furanmethanol acetate & $231.23 \pm 14.30$ & $105.97 \pm 4.22$ \\
\hline & Acetic acid 2-phenylethyl ester & $1193.05 \pm 32.56$ & $495.92 \pm 7.01$ \\
\hline \multirow{5}{*}{ Aldehydes } & 3-Furaldehyde & $95.88 \pm 2.74$ & $367.65 \pm 4.70$ \\
\hline & Benzaldehyde & $414.71 \pm 3.33$ & $303.41 \pm 2.41$ \\
\hline & Benzeneacetaldehyde & $114.65 \pm 3.29$ & $203.71 \pm 2.62$ \\
\hline & (E)-2-Octenal & $208.86 \pm 5.56$ & - \\
\hline & 2-Undecenal & $84.14 \pm 0.81$ & $5.06 \pm 0.75$ \\
\hline Ketones & Dihydro-5-pentyl-2(3H)-furanone & $174.52 \pm 3.20$ & $306.76 \pm 4.78$ \\
\hline Pyrazines & Tetramethylpyrazine, & $722.33 \pm 5.17$ & $1038.16 \pm 11.43$ \\
\hline \multirow{2}{*}{ Others } & 2-Pentadecyl-1,3-dioxepane & $30.31 \pm 0.49$ & $221.92 \pm 4.89$ \\
\hline & Creosol & $146.03 \pm 4.26$ & $50.82 \pm 1.99$ \\
\hline
\end{tabular}

Note: "-" means not detected by HS-SPME-GC-MS.

\section{Conclusions}

In this study, HBV was made, using $\mathrm{HB}$ as the raw material, based on the process of SAV, a famous vinegar in China, in which sorghum is usually used as the raw material. The results showed that HB may be more appropriate than sorghum as the raw material, because the contents of starch and protein, the main components in brewing vinegar, were higher in HB. In addition, compared with SV, the acid and ester VFCs in HBV were superior.

Supplementary Materials: The following are available online at https: / www.mdpi.com/article / 10.3390/app11136039/s1, Table S1: VFCs in aged HBV and SV detected by HS-SPME/GC-MS.

Author Contributions: Conceptualization, F.C.; data curation, formal analysis and visualization, H.Z.; investigation, resources and software, J.Z. and F.L.; methodology and validation, Y.Z.; writingreview and editing and funding acquisition, F.C. All authors have read and agreed to the published version of the manuscript.

Funding: This research received no external funding.

Institutional Review Board Statement: Not applicable.

Informed Consent Statement: Not applicable.

Data Availability Statement: Not applicable.

Conflicts of Interest: The authors declare no conflict of interest. 


\section{References}

1. Obadi, M.; Sun, J.; Xu, B. Highland barley: Chemical composition, bioactive compounds, health effects, and applications. Food Res. Int. 2021, 140, 110065. [CrossRef] [PubMed]

2. Huang, L.; Dong, J.; Zhang, K.; Zhu, Y.; Qu, L. Thermal processing influences the physicochemical properties, in vitro digestibility and prebiotics potential of germinated highland barley. LWT 2020, 140, 110814. [CrossRef]

3. Kan, J.; Hong, Q. Research progress of bioactive ingredients and physiological functions in Qingke. Food Sci. Technol. 2020, 38, 11-20.

4. Al-Ansi, W.; Mahdi, A.A.; Al-Maqtari, Q.A.; Mushtaq, B.S.; Ahmed, A.; Karrar, E.; Mohammed, J.K.; Fan, M.; Li, Y.; Qian, H.; et al. The potential improvements of naked barley pretreatments on GABA, $\beta$-glucan, and antioxidant properties. $L W T$ 2020, 130, 109698. [CrossRef]

5. Wang, C.; Pan, Z.; Nima, Z.; Tang, Y.; Cai, P.; Liang, J.; Deng, G.; Long, H.; Yu, M. Starch granule-associated proteins of hull-less barley (Hordeum vulgare L.) from the Qinghai-Tibet Plateau in China. J. Sci. Food Agric. 2011, 91, 616-624. [CrossRef]

6. Li, W.; Xiao, X.; Zhang, W.; Zheng, J.; Luo, Q.; Ouyang, S.; Zhang, G. Compositional, morphological, structural and physicochemical properties of starches from seven naked barley cultivars grown in China. Food Res. Int. 2014, 58, 7-14. [CrossRef]

7. Xiao, X.; Tan, C.; Sun, X.; Zhao, Y.; Zhang, J.; Zhu, Y.; Bai, J.; Dong, Y.; Zhou, X. Effects of fermentation on structural characteristics and in vitro physiological activities of barley $\beta$-glucan. Carbohydr. Polym. 2020, 231, 115685. [CrossRef]

8. Lin, S.; Guo, H.; Gong, J.D.B.; Lu, M.; Lu, M.; Wang, L.; Zhang, Q.; Qin, W.; Wu, D. Phenolic profiles, $\beta$-glucan contents, and antioxidant capacities of colored Qingke (Tibetan hulless barley) cultivars. J. Cereal Sci. 2018, 81, 69-75. [CrossRef]

9. Zhu, Y.; Li, T.; Fu, X.; Brennan, M.; Abbasi, A.; Zheng, B.; Liu, R. The use of an enzymatic extraction procedure for the enhancement of highland barley (Hordeum vulgare L.) phenolic and antioxidant compounds. Int. J. Food Sci. Technol. 2016, 51. [CrossRef]

10. Kinner, M.; Nitschko, S.; Sommeregger, J.; Petrasch, A.; Linsberger-Martin, G.; Grausgruber, H.; Berghofer, E.; Siebenhandl-Ehn, S. Naked barley-Optimized recipe for pure barley bread with sufficient beta-glucan according to the EFSA health claims. J. Cereal Sci. 2011, 53, 225-230. [CrossRef]

11. Guo, X.; Gao, F.; Zhu, K. Effect of fresh egg white addition on the quality characteristics and protein aggregation of oat noodles. Food Chem. 2020, 330, 127319. [CrossRef] [PubMed]

12. Zhang, Y.; Yin, L.; Rasheed, H.A.; Xia, X.; Tekliye, M.; Li, Z.; Li, J.; Dong, M. Effects of chitosan on the physicochemical properties, in vitro starch digestibility, antimicrobial potentials, and antioxidant activities of purple highland barley noodles. LWT 2020, 132, 109802. [CrossRef]

13. Chen, S.; Chen, L.; Chen, L.; Ren, X.; Ge, H.; Li, B.; Ma, G.; Ke, X.; Zhu, J.; Li, L.; et al. Potential probiotic characterization of Lactobacillus reuteri from traditional Chinese highland barley wine and application for room-temperature-storage drinkable yogurt. J. Dairy Sci. 2018, 101, 5780-5788. [CrossRef]

14. Wu, Q.Y. Research on the Barley Vinegar Brewing Technology and Properties Comparison. Master's Thesis, Southwest University, Chongqing, China, 2017.

15. Mazza, S.; Murooka, Y. Vinegars through the Ages. In Vinegars of the World; Solieri, L., Giudici, P., Eds.; Springer: Milano, Italy, 2009; pp. 17-39. [CrossRef]

16. Solieri, L.; Giudici, P. Vinegars of the World. In Vinegars of the World; Solieri, L., Giudici, P., Eds.; Springer: Milano, Italy, 2009; pp. 1-16. [CrossRef]

17. Liu, D.; Yang, Z.; Beeftink, R.; Ooijkaas, L.; Rinzema, A.; Chen, J.; Tramper, J. Chinese vinegar and its solid-state fermentation process. Food Rev. Int. 2004, 20, 407-424. [CrossRef]

18. Chen, F.; Li, L.; Qu, J.; Chen, C. Cereal vinegars made by solid-state fermentation in China. In Vinegars of the World; Solieri, L., Giudici, P., Eds.; Springer: Milano, Italy, 2009; pp. 243-259. [CrossRef]

19. Nie, Z.; Zheng, Y.; Du, H.; Xie, S.; Wang, M. Dynamics and diversity of microbial community succession in traditional fermentation of Shanxi aged vinegar. Food Microbiol. 2015, 47, 62-68. [CrossRef] [PubMed]

20. Giudici, P.; Corradini, G.; Bonciani, T.; Wu, J.; Chen, F.; Lemmetti, F. The flavor and taste of cereal Chinese vinegars. Acetic Acid Bact. 2017, 6. [CrossRef]

21. Liang, J.; Xie, J.; Hou, L.; Zhao, M.; Zhao, J.; Cheng, J.; Wang, S.; Sun, B. Aroma constituents in Shanxi aged vinegar before and after aging. J. Agric. Food Chem. 2016, 64. [CrossRef] [PubMed]

22. Zheng, X.; Tabrizi, M.; Nout, M.J.; Han, B. Daqu-A traditional Chinese liquor fermentation starter. J. Inst. Brew. 2011, 117, 82-90. [CrossRef]

23. Li, S.; Li, P.; Feng, F.; Luo, L. Microbial diversity and their roles in the vinegar fermentation process. Appl. Microbiol. Biotechnol. 2015, 99, 4997-5024. [CrossRef]

24. $\mathrm{Wu}$, J.; Ma, Y.; Zhang, F.; Chen, F. Biodiversity of yeasts, lactic acid bacteria and acetic acid bacteria in the fermentation of "Shanxi aged vinegar", a traditional Chinese vinegar. Food Microbiol. 2012, 30, 289-297. [CrossRef]

25. Xia, T.; Yao, J.; Zhang, J.; Duan, W.; Zhang, B.; Xie, X.; Xia, M.; Song, J.; Zheng, Y.; Wang, M. Evaluation of nutritional compositions, bioactive compounds, and antioxidant activities of Shanxi aged vinegars during the aging process. J. Food Sci. 2018, 83, 2638-2644. [CrossRef] [PubMed]

26. Huang, C.; Yin, H.; Zhou, J. Continuous determination of the content of total acid and ester in vinegar. Food Ferment. Ind. 2001, 12, $41-43$. 
27. Zhang, T.; Wang, Q.; Li, J.; Zhao, S.; Qie, M.; Wu, X.; Bai, Y.; Zhao, Y. Study on the origin traceability of Tibet highland barley (Hordeum vulgare L.) based on its nutrients and mineral elements. Food Chem. 2021, 346, 128928. [CrossRef]

28. Madu, J.O.; Agboola, B.O. Bioethanol production from rice husk using different pretreatments and fermentation conditions. 3 Biotech 2018, 8, 15. [CrossRef]

29. Wang, Y.; Qiu, S.; Wang, Y.; Jang, C. Process optimization of acetic acid fermentation of hawthorn vinegar. Agric. Sci. Technol. 2016, 17, 420-423.

30. Duan, W.; Xia, T.; Zhang, B.; Li, S.; Zhang, C.; Zhao, C.; Song, J.; Wang, M. Changes of physicochemical, bioactive compounds and antioxidant capacity during the brewing process of Zhenjiang aromatic vinegar. Molecules 2019, 24, 3935. [CrossRef] [PubMed]

31. Chen, Q.; Ding, J.; Cai, J.; Sun, Z.; Zhao, J. Simultaneous measurement of total acid content and soluble salt-free solids content in Chinese vinegar using Near-infrared Spectroscopy. J. Food Sci. 2012, 77, C222-C227. [CrossRef]

32. Chen, J.; Chen, Q.; Guo, Q.; Ruan, S.; Ruan, H.; He, G.; Gu, Q. Simultaneous determination of acetoin and tetramethylpyrazine in traditional vinegars by HPLC method. Food Chem. 2010, 122, 1247-1252. [CrossRef]

33. Zhu, H.; Zhu, J.; Wang, L.; Li, Z. Development of a SPME-GC-MS method for the determination of volatile compounds in Shanxi aged vinegar and its analytical characterization by aroma wheel. J. Food Sci. Technol. 2016, 53, 171-183. [CrossRef] [PubMed]

34. Chen, C.; Chen, H.; Zhang, Y.; Thomas, H.R.; Frank, M.H.; He, Y.; Xia, R. TBtools: An integrative toolkit developed for interactive analyses of big biological data. Mol. Plant 2020, 13, 1194-1202. [CrossRef]

35. Kalil, S.J.; Maugeri, F.; Rodrigues, M.I. Response surface analysis and simulation as a tool for bioprocess design and optimization. Process. Biochem. 2000, 35, 539-550. [CrossRef]

36. Nie, Z.; Zheng, Y.; Xie, S.; Zhang, X.; Song, J.; Xia, M.; Wang, M. Unraveling the correlation between microbiota succession and metabolite changes in traditional Shanxi aged vinegar. Sci. Rep. 2017, 7, 9240. [CrossRef]

37. Wu, J.; Gullo, M.; Chen, F.; Giudici, P. Diversity of Acetobacter pasteurianus strains isolated from solid-state fermentation of cereal vinegars. Curr. Microbiol. 2010, 60, 280-286. [CrossRef] [PubMed]

38. Yu, J.; Huang, L.; Huang, Q.; Ma, C.; Cao, Y. Main ingredient change trend during the aging process of Xiangxi original musk vinegar. Grain Sci. Technol. Econ. 2013, 38, 58-60.

39. Chen, T.; Gui, Q.; Shi, J.; Zhang, X.; Chen, F. Analysis of variation of main components during aging process of Shanxi aged vinegar. Acetic Acid Bact. 2013, 2, 6. [CrossRef]

40. Ishihara, S.; Inaoka, T.; Nakamura, T.; Kimura, K.; Sekiyama, Y.; Tomita, S. Nuclear magnetic resonance- and gas chromatography/mass spectrometry-based metabolomic characterization of water-soluble and volatile compound profiles in cabbage vinegar. J. Biosci. Bioeng. 2018, 126, 53-62. [CrossRef] [PubMed]

41. Gerbi, V.; Zeppa, G.; Antonelli, A.; Carnacini, A. Sensory characterisation of wine vinegars. Food Qual. Prefer. 1997, 8, 27-34. [CrossRef]

42. Tagliazucchi, D.; Verzelloni, E.; Conte, A. Contribution of melanoidins to the antioxidant activity of traditional balsamic vinegar during aging. J. Food Biochem. 2010, 34, 1061-1078. [CrossRef]

43. Chou, C.; Liu, C.; Yang, D.; Wu, Y.; Chen, Y. Amino acid, mineral, and polyphenolic profiles of black vinegar, and its lipid lowering and antioxidant effects in vivo. Food Chem. 2015, 168, 63-69. [CrossRef] [PubMed]

44. Li, W.; Liu, M.; Xu, Y.; Feng, Y.; Che, J.; Wang, G.; Zheng, J. Combination of quercetin and hyperoside has anticancer effects on renal cancer cells through inhibition of oncogenic microRNA-27a. Oncol. Rep. 2013, 31. [CrossRef]

45. Ruan, Z.; Yang, Y.; Zhou, Y.; Wen, Y.; Ding, S.; Liu, G.; Wu, X.; Liao, P.; Deng, Z.; Assaad, H.; et al. Metabolomic analysis of amino acid and energy metabolism in rats supplemented with chlorogenic acid. Amino Acids 2014, 46, 2219-2229. [CrossRef]

46. Kim, H.R.; Park, C.G.; Jung, J.Y. Acacetin (5,7-dihydroxy-4'-methoxyflavone) exhibits in vitro and in vivo anticancer activity through the suppression of NF-кB/Akt signaling in prostate cancer cells. Int. J. Mol. Med. 2014, 33, 317-324. [CrossRef] [PubMed]

47. Liu, D.; Liu, F.; Kang, S.; Sun, J.; Wang, H.; Xu, N. Changes of flavor substances and functional active components in fumigation process of traditional Shanxi aged vinegar. China Brew. 2021, 40, 163-169.

48. Nie, J.; Li, Y.; Qin, X.; Li, Z. Recent progress in chemical composition of grain-derived traditional vinegar. Food Sci. 2018, 39, 322-328.

49. Mäkelä, N.; Rosa-Sibakov, N.; Wang, Y.; Mattila, O.; Nordlund, E.; Sontag-Strohm, T. Role of $\beta$-glucan content, molecular weight and phytate in the bile acid binding of oat $\beta$-glucan. Food Chem. 2021, 358, 129917. [CrossRef] [PubMed]

50. Zheng, Y.; Zhao, C.; Wu, Y.; Liu, J.; Cheng, C. Composition of characteristic flavor components and analysis of flavor wheel for Shanxi aged vinegar. J. Food Sci. Technol. 2019, 37, 24-34.

51. Frauendorfer, F.; Schieberle, P. Changes in key aroma compounds of Criollo cocoa beans during roasting. J. Agric. Food Chem. 2008, 56, 10244-10251. [CrossRef]

52. Kotseridis, Y.; Baumes, R. Identification of impact odorants in Bordeaux red grape juice, in the commercial yeast used for its fermentation, and in the produced wine. J. Agric. Food Chem. 2000, 48, 400-406. [CrossRef]

53. Jordán, M.J.; Shaw, P.E.; Goodner, K.L. Volatile components in aqueous essence and fresh fruit of Cucumis melo cv. Athena (muskmelon) by GC-MS and GC-O. J. Agric. Food Chem. 2001, 49, 5929-5933. [CrossRef]

54. Al-Dalali, S.; Zheng, F.; Sun, B.; Zhou, C.; Li, M.; Chen, F. Effects of different brewing processes on the volatile flavor profiles of Chinese vinegar determined by HS-SPME-AEDA with GC-MS and GC-O. LWT 2020, 133, 109969. [CrossRef]

55. Yu, Y.; Lu, Z.; Yu, N.; Xu, W.; Li, G.; Shi, J.; Xu, Z. HS-SPME/GC-MS and chemometrics for volatile composition of Chinese traditional aromatic vinegar in the Zhenjiang region. J. Inst. Brew. 2012, 118, 133-141. [CrossRef] 
56. Kunjapur, A.M.; Prather, K.L. Microbial engineering for aldehyde synthesis. Appl. Environ. Microbiol. 2015, 81, $1892-1901$. [CrossRef] [PubMed]

57. Xiao, Z.; Dai, S.; Niu, Y.; Yu, H.; Zhu, J.; Tian, H.; Gu, Y. Discrimination of Chinese vinegars based on headspace solid-phase microextraction-gas chromatography mass spectrometry of volatile compounds and multivariate analysis. J. Food Sci. 2011, 76, C1125-C1135. [CrossRef]

58. Chen, H.; Chen, T.; Giudici, P.; Chen, F. Vinegar functions on health: Constituents, sources, and formation mechanisms. Compr. Rev. Food Sci. Food Saf. 2016, 15, 1124-1138. [CrossRef] [PubMed] 